\title{
CADAVERIC STUDY OF ABNORMAL COMMUNICATION BETWEEN CORDS AND BRANCHES OF BRACHIAL PLEXUS
}

\section{Zarna K. Patel ${ }^{* 1}$, Sudarshan Gupta ${ }^{2}$, Sucheta Chaudhary ${ }^{3}$.}

${ }^{*_{1}}$ Assistant Professor, Department of Anatomy, GMERS Medical College, Gandhinagar, Gujarat, India.

${ }^{2}$ Associate Professor, Department of Anatomy, GMERS Medical College Gandhinagar, , Gujarat, India.

${ }^{3}$ Professor and Head, B.J.Medical College, Ahemdabad, Gujarat, India.

\section{ABSTRACT}

Background: Brachial Plexus is formed by anterior rami of inferior four cervical nerves C5,C6,C7,C8 and first thoracic nerve T1.It has roots, trunk, divisions, cords and terminal branches. Variations in communication of branches and cords are commonly observed.

Materials and Methods: In this study, 30 cadavers were used in which 60 upperlimb each of right and left, the axilla region is carefully dissected out during routine dissection.

Results: In Present study among 60 upper limbs abnormal communications were observed in 8 cadavers.

Conclusion: Abnormal communication between branches and cords could be vary useful for orthopedician, neurosurgeons, anesthetists, radiologists, general surgeons in various surgical operations like surgery of shoulder joint of humerus, nerve blocking etc. So this study is done.

KEY WORDS: Brachial Plexus, Median nerve, Musculocutaneous Nerve.

Address for Correspondence: Dr. Zarna K. Patel, Assistant Professor, Department of Anatomy, GMERS Medical College, Gandhinagar. Civil Hospital Campus, Pathikasharam, Sector-12, Gandhinagar 382012, Gujarat, India. Moble No: 9909919721 E-Mail: zdpdoctor@yahoo.com

\begin{tabular}{|l|l|}
\hline \multicolumn{3}{|c|}{ Access this Article online } \\
\hline Quick Response code & $\begin{array}{l}\text { Web site: International Journal of Anatomy and Research } \\
\text { ISSN 2321-4287 } \\
\text { www.ijmhr.org/ijar.htm }\end{array}$ \\
\cline { 2 - 3 } & \multicolumn{2}{c|}{$\begin{array}{l}\text { Accepted: 03 Apr } 2017 \\
\text { DoI: 10.16965/ijar.2017.162 }\end{array}$} & $\begin{array}{l}\text { Received: 26 Feb 2017 } \\
\text { Reer Review: 27 Feb 2017: None }\end{array}$ & $\begin{array}{l}\text { Published (O): } 30 \text { Apr } 2017 \\
\text { Published (P): } 30 \text { Apr } 2017\end{array}$ \\
\hline
\end{tabular}

\section{INTRODUCTION}

A good awareness of human neural system anatomy can be a passport to success in elective neurosurgeries [1]. Due to critical conditions of traumatic patients, a speedy surgical promptitude in emergency circumstances requires knowledge of the human neural system anatomy [2].

Variations in human anatomy are one of the most important challenges. The extremities, particularly upper limbs, are susceptible to traumas, but unfortunately, the anatomical variations of brachial plexus are not rare $[3,4]$. More than $50 \%$ of anatomical variations in cadaveric studies of human neural system have been reported to belong to the brachial plexus [5-7]. The plexus supplies both motor and sensory innervations to the upper limb as well as the extrinsic thoracic muscles [8].

The brachial plexus is constituted by the ventral rami of spinal cervical nerves including C5-C8 and the first thoracic spinal nerve T1 [9]. 
A complex of nerves originating from the neck and axilla shapes the brachial plexus. The brachial plexus extends laterally towards the cervico-axillary canal located below the clavicle, but above the first rib and then enters the axilla through this passage. The brachial plexus provides a network of terminal nerves innervating the upper limb $[10,11]$.

Three trunks lie in human brachial plexus, stemming from the spinal roots of C5-T1. The ventral rami of $\mathrm{C} 5$ and $\mathrm{C} 6$ are joined to make the superior trunk. C7 root continues and becomes the middle trunk, and the inferior trunk is shaped by the union of C 8 and T1 roots [7], each of which splits into anterior and posterior divisions in the floor of the posterior triangle of the neck. At the upper border of the first rib, these divisions form cords which are related to the second part of the axillary artery. All posterior divisions join to form posterior cord ( $\mathrm{C} 5$ to $\mathrm{T} 1)$, anterior divisions of the superior and middle trunks join to form lateral cord ( $\mathrm{C} 5$ to $\mathrm{C} 7$ ), and anterior division from inferior trunk forms the medial cord (C8 to T1). Just distal to the inferior border of the pectoralis minor muscle, near the third part of the axillary artery, the cords give off their terminal branches, including the axillary, musculocutaneous, radial, median, and ulnar nerves [7]. Variations involving the brachial plexus has been reported and discussed by many researchers [9-11] and they were found to involve different parts of it.

\section{MATERIALS AND METHODS}

The present study was carried out at anatomy department of GMERS Medical CollegeGandhinagar, GMERS Medical College-Dharpur, Patan . In this study, 30 cadavers were used in which 60 upper limb each of right and left, the axilla region is carefully dissected out during routine dissection. Among 60 upper limb we found observations in following cases:

Study of Duration: One and half year, 20152016.

\section{OBSERVATIONS}

Cadaver 1: This is a male cadaver. In this cadaver bilateral variation in brachial plexus were observed, i.e. the MCN (Musculocutaneous nerve) arises from the lateral cord passes beneth the coracobrachoalis muscle Instead of piercing it. After passing it give few fibers to median nerve and abnormally joins with the median nerve.No other variations are found. (Figure 1)

Fig. 1: Showing the bilateral variations in brachial plexus, where Musculocuateous nerve arises from the lateral cord and variant course of it.

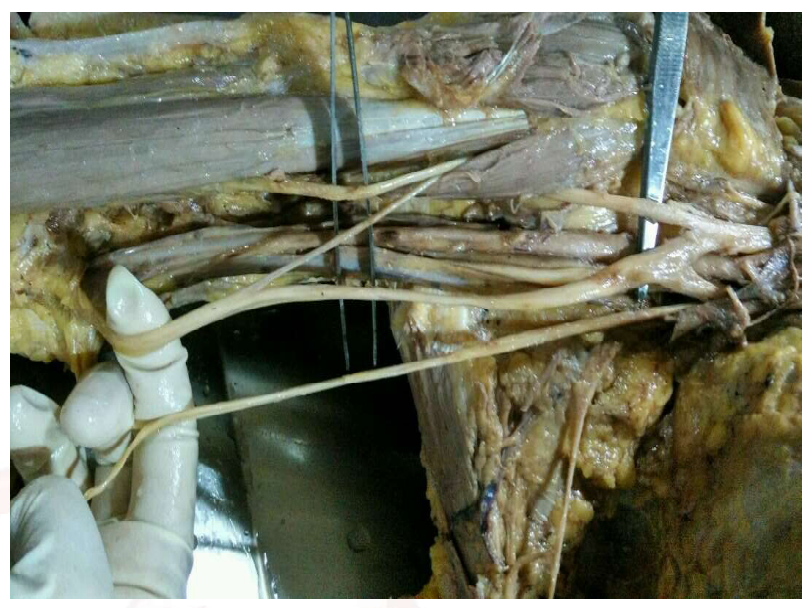

Cadaver 2: This is male cadaver, Variations are bilateral, i.e. ulnar nerve receives fibers from lateral cord and medial root of median nerve. Median nerve has additional root coming from lateral cord and joins with ulnar nerve. No variation present in Musculocutaneous nerve (Figure 2)

Fig. 2: Showing the bilateral variations in brachial plexus, where ulnar nerve receives fibers from the lateral cord and medial root of median nerve.

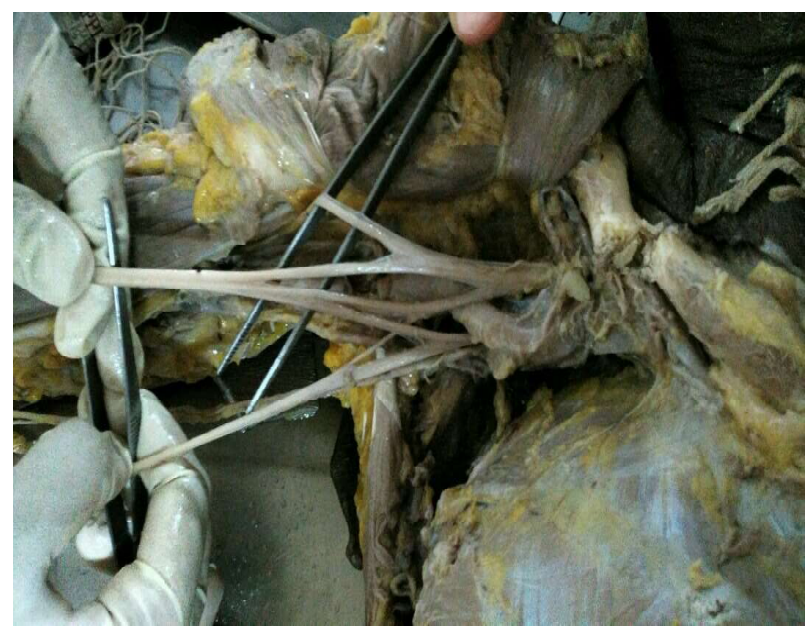

Cadaver 3: This is female cadaver, variations are bilateral. In this cadaver musculo-cutaneous nerve is giving some fibers to median nerve. Abnormal communication between musculo-cutaneous nerve and median nerve. Musculocutaneous nerve is not piercing to coracho-brachialis muscle. (Figure 3) 
Fig. 3: Showing the bilateral variations in brachial plexus, where musculo-cutaneous nerve is giving some fibers to median nerve and an abnormal communication with median nerve.

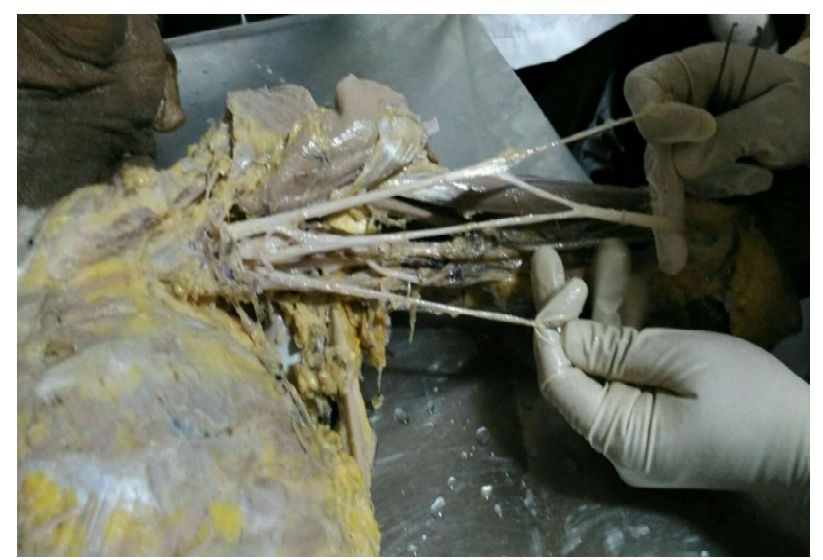

Cadaver 4: This is male cadaver. In this cadaver also bilateral variations are present. Abnormal communication is present between lateral cord and medial root of median nerve. Musculocutaneous nerve is normal. (Figure-4)

Fig. 4: Showing the bilateral variations in brachial plexus, an abnormal communication is present between lateral cord and medial root of median nerve.

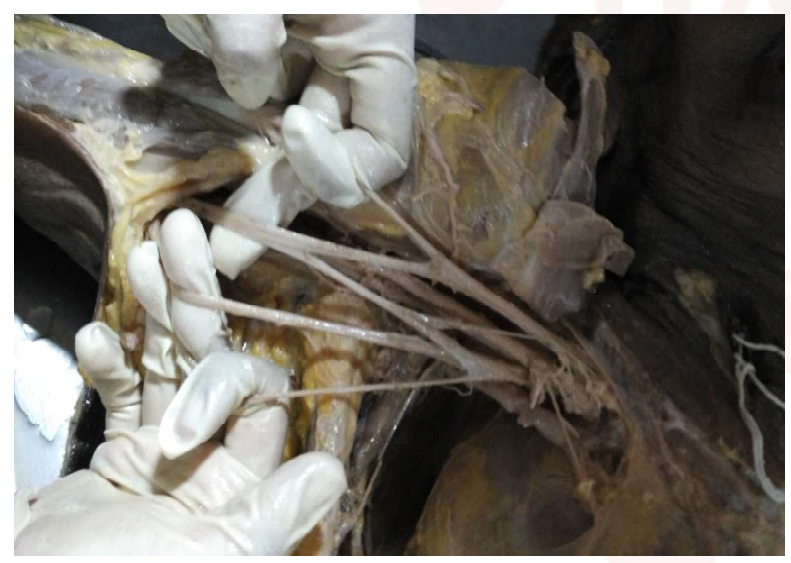

In the present study out of 60 upper limbs we found abnormal communications in 8 upper limbs. So we found $13.33 \%$ variations.

\section{DISCUSSION}

Variations involving the brachial plexus are not uncommon and have been linked with factors influencing the mechanism of limb muscles and peripheral nerves development during embryonic life [12].These variations are clinically and surgically important.

In the present study, the MN was three out of 60 cases, communication between the MCN and the median nerve was seen in 4 upper limbs (6.66\%), in 4 upper limbs (6.66\%) MCN not piercing the corachobrachialis. In 2 upper limbs
(3.33\%) ulnar nerve receiving fibers from lateral cord and medial root of median nerveand the rest of them are normal. In 2 upper limbs (3.33\%) communication present between lateral cord and medial root of median nerve.

Information about the connections between the $\mathrm{MCN}$ and the MN could be very useful in relation to surgical operations of the humerus bone and shoulder joint [15]. During the surgeries of shoulder region, the MCN must be identified and kept safe from probable injuries that could occur by pressure of the retractors which the surgeon places un-der the coracoid process. The muscles could get injured as well as the nerves in dislocation of the shoulder joint, grafting of the coracoid process and also arthroscopies[16].

Communications between musculocutaneous and median nerve are also well documented (Yang et al., 1995; Chiarapattanakom et al., 1998; Choi et al., 2002) .Venieratos and Anagnostopoulou (1998) in their work on brachial plexus stated that communication between musculocutaneous and median nerve is the most frequent of all the variations [18].

In our study also we observed a communication between median nerve and musculocutaneous nerve found in $6.66 \%$. Communications were also seen in the branches of the medial and posterior cords, as the medial root of median nerve gave a communicating twig to the ulnar nerve which could be the fibers that median root of median received from the lateral root as described by Hollinshead (1958). He stated that ulnar nerve usually receives fibers from seventh cervical nerve by receiving a contribution from the LC. Iyer and Fenichel (1976), Gutmann (1977), Crutchfield and Gutmann (1980) and Snock et al. (1991) reported the communication between median and ulnar nerve in forearm and hand.

The communication between ulnar and radial nerve is not well documented $(17,18)$.In present study also in $3.33 \%$ cases we found communication between ulnar nerve and lateral cord and medial root of median nerve as described by Hollinshed.

We could not find any communication between ulnar and radial nerve. To block the nerves of brachial plexus, the anesthetists need to have 
proper knowledge of such variations so they can block the specific nerve properly. Orthopedic surgeons also must be aware of such variations to prevent nerve injuries in routine and reconstructive operations of the arm. Because of the close relationship that the lateral root of $\mathrm{MN}$ has with the axillary artery, compression of the axillary artery by the $\mathrm{MN}$ in certain postural maneuvers of the shoulder joint may lead to arterial blood insufficiency as well as the ischemic pain [19].

Embryological Note: Abnormal communication between the branches and cord of brachial plexus can be explained by neuronal growth cone behavior during embryonic development which are mediated by intracellular signaling pathways that link guidance receptors regulated by expression of chemo-attractants and chemo-repellants, to the cytoskeleton [20]. Alterations in signaling between mesenchymal cells and neuronal growth cones can lead to significant variations which once formed would persist after birth. In the present case where the brachial plexus showed multiplevariations might be a result from bilateral alterations in mesenchymal cells and growth cones signaling.

\section{CONCLUSION}

Knowledge about the connections between median nerve and musculocutaneous nerve can be very useful for surgical operations of humerus bone and shoulder joints. So, more information can be collect by such anatomical observational study. Knowledge of Brachial plexus variation has important anatomical, surgical and clinical applications especially in relation to Trauma and Surgical procedures of upper limb. The present case provides additional knowledge on Brachial plexus variations to clinicians which may help to avoid damage during surgical procedures related to Plastic and reconstructive surgery. It is also important to be aware of these variations during Brachial plexus block and in nerve entrapment syndromes involving different branches of Brachial plexus.

\section{Conflicts of Interests: None}

\section{REFERENCES}

[1]. Butz JJ, Shiwlochan DG , Brown KC, Prasad AM, Murlimanju BV, Viswanath S. Bilateral variations of brachial plexus involving the median nerve and lateral cord: an anatomical case study with clinical implications. Australas Med J. 2014;7(5):22731.

[2]. Parchand MP, Patil ST. Absence of musculocutaneous nerve with variations in course and distribution of the median nerve. AnatSci Int. 2013;88(1):5860.

[3]. Aydin ME, Kale A, Edizer M, Kopuz C, Demir MT, Corumlu U. Absence of the musculocutaneous nerve together with unusual innervation of the median nerve. Folia Morphol (Warsz). 2006;65(3):228-31.

[4]. Soleymanha M, Mobayen M, Asadi K, Adeli A, Haghparast-Ghadim-Limudahi Z. Survey of 2582 cases of acute orthopedic trauma. Trauma Mon. 2014; 19(4):e16215.

[5]. Chaudhary P, Singla R, Arora K, Kalsey G. Formation and branching pattern of cords of brachial plexusa cadaveric study in north Indian population. Int J Ana Res. 2014;2(1):225-33.

[6]. Budhiraja V, Rastogi R, Asthana AK. Variations in the formation of the median nerve and its clinical correlation. Folia Morphol (Warsz). 2012;71(1):2830.

[7]. Uysal II, Seker M, Karabulut AK, Buyukmumcu M, Ziylan T. Brachial plexus variations in human fetuses. Neurosurgery. 2003;53(3):676-84.

[8]. Agur AM, Dalley AF. Grant's atlas of anatomy. 13th ed. Philadelphia: Lippincott Williams \& Wilkins; 201

[9]. Dent EW, Tang F, Kalil K. Axon guidance by growth cones and branches: Common cytoskeletal and signaling mechanisms. Neuroscientist. 2003;9(5):343353

[10]. Havaldar PP, Gupta A, Rajasekhar HV. Case report: Variation in the formation of brachial plexus and its relation with axillary artery. Current Neurobiology. 2012;3(1):7-9.

[11]. Johnson EO, Vekris M, Demesticha T, Soucacos PN. Neuroanatomy of the brachial plexus: normal and variant anatomy of its formation. SurgRadiol Anat. 2010;32(3):291-7.

[12]. Venieratos D, Anangnostopoulou S. Classisication of communications between the musculocutaneous and median nerves.Clinical Anatomy.1998; 11(5),327-331.

[13]. Williams PI, Bannister LH, Berry MM, Collins P, Dyson M, Grays Anatomy. In Nervous System. 38thedition. Churchil Livingston: Edinburgh;1995;1266-1274.

[14]. Haeri GB, Wiley AM. Shoulder impingement syndrome, results of operative release. Clinical Orthopaedics.1982;168:128-132.

[15]. Flatow EL, Bigliani LU, April EW. An anatomic study of the musculocutaneous nerve and its relationship with the coracoid process. Clinical Orthopaedics and Related Re-search.1989;244:166-171.

[16]. Le Minor JM. A rare variant of the median and musculocu-taneous nerve in man. Archives of Anatomy, Histology and Embryology. 1992;73:3342. 
[17]. Gupta M et al,Anomalus communication in branches of brachial plexus. J. Anat.Soc.India. 2005;54(1):2225.

[18]. Sontakke BR, Tarnekar AM, Waghmare JE, Ingole IV. An unusual case of asymmetrical formation and distribution of median nerve. International Journal of Anatomical Vari-ations. 2011;4:57-60.

[19]. Dent EW, Tang F, Kalil K. Axon guidance by growth cones and branches: Common cytoskeletal and signaling mechanisms. Neuroscientist. 2003;9(5):343353.
[20]. Gabriel J Mchonde et al. Bilateral multiple variations in the formation of brachial plexus. Int J Anat Res 2013;1(2):78-82.

How to cite this article:

Zarna K. Patel, Sudarshan Gupta, Sucheta Chaudhary. CADAVERIC STUDY OF ABNORMAL COMMUNICATION BETWEEN CORDS AND BRANCHES OF BRACHIAL PLEXUS. Int J Anat Res 2017;5(2.1):37413745. DOI: 10.16965/ijar.2017.162 